research support from: The IRCCS Istituto Giannina Gaslini (IGG), where NR works as full-time public employee has received contributions (>10.000 USD each) from the following industries in the last 3 years: Bristol Myers Squibb, Eli Lilly, F Hoffmann-La Roche, GlaxoSmithKline, Janssen, Novartis, Pfizer, Sobi. This funding has been reinvested for the research activities of the hospital in a fully independent manner, without any commitment with third parties., Grant Schulert Speakers bureau: Novartis, Consultant of: SOBI, Alyssa Sproles: None declared, Sherry Thornton: None declared, Gabriel Vega Cornejo Speakers bureau: AbbVie, Grant/research support from: Bristol Myers Squibb, Eli Lilly, Janssen, Parexel, Sanofi, Jordi Anton Speakers bureau: AbbVie, Gebro, GlaxoSmithKline, Novartis, Pfizer, Roche, Sobi, Consultant of: AbbVie, Gebro, GlaxoSmithKline, Novartis, Pfizer, Roche, Sobi, Grant/research support from: AbbVie, Amgen, Gebro, GlaxoSmithKline, Lilly, Novartis, Novimmune, Pfizer, Roche, Sanofi, Sobi, Ruben Cuttica Speakers bureau: AbbVie, Bristol Myers Squibb, GlaxoSmithKline, Lilly, Novartis, Pfizer, Roche, UCB, Paid instructor for: AbbVie, Novartis, Pfizer, Roche, Consultant of: AbbVie, Bristol Myers Squibb, GlaxoSmithKline, Lilly, Novartis, Pfizer, Roche, UCB, Michael Henrickson: None declared, Ivan Foeldvari Consultant of: Bristol Myers Squibb, Gilead, Hexal, MEDAC, Novartis, Pfizer, Sanofi, Daniel Kingsbury Consultant of: Pfizer, Margarita Askelson Consultant of: Currently working for Syneos Health providing services to Bristol Myers Squibb, Jinqi Liu Shareholder of: Bristol Myers Squibb, Employee of: Bristol Myers Squibb, Sumanta Mukherjee Shareholder of: Bristol Myers Squibb, GlaxoSmithKline, Employee of: Bristol Myers Squibb, GlaxoSmithKline, Robert Wong Shareholder of: Bristol Myers Squibb, Employee of: Bristol Myers Squibb, Daniel J Lovell Speakers bureau: Genentech, Wyeth Pharm, Consultant of: Abbott, Amgen, AstraZeneca, Boehringer Ingelheim, Celgene, GlaxoSmithKline, Hoffman-La Roche, Novartis, Pfizer, Regeneron, Takeda, UBC, Wyeth Pharma, Xoma, Alberto Martini Speakers bureau: AbbVie, Novartis, Consultant of: AbbVie, Eli Lilly, EMD Serono, Idorsia, Janssen, Novartis, Pfizer, Alexei Grom Consultant of: AB2Bio, Novartis, Sobi (Novlmmune), Grant/research support from: AB2Bio, Novartis, Sobi (Novlmmune), Hermine Brunner Speakers bureau: GlaxoSmithKline, Novartis, Pfizer, Roche, Paid instructor for: Novartis, Pfizer (funds go to CCHMC/employer), Consultant of: Boehringer Ingelheim, Bristol Myers Squibb, GlaxoSmithKline, Janssen, Merck, Novartis, Pfizer, Roche, UCB (funds go to CCHMC/employer), Grant/research support from: Bristol Myers Squibb, Pfizer (funds go to CCHMC/ employer).

DOI: 10.1136/annrheumdis-2021-eular.1081

\section{POS0077 PHYSICAL ACTIVITY AND SPORT PARTICIPATION A COMPARISON BETWEEN CHILDREN AND ADOLESCENTS WITH JUVENILE IDIOPATHIC ARTHRITIS (JIA) AND THE GERMAN GENERAL POPULATION}

F. Milatz $^{1}$, M. Niewerth ${ }^{1}$, J. Klotsche ${ }^{1}$, J. Hörstermann ${ }^{1}$, S. Hansmann ${ }^{2}$, T. Kallinich ${ }^{3}$, C. Rietschel ${ }^{4}$, R. Trauzeddel ${ }^{5}$, J. Peitz ${ }^{6}$, M. Hartmann ${ }^{7}$, H. Girschick ${ }^{8}$, K. Minden ${ }^{1,9}$. 'German Rheumatism Research Centre, Epidemiology and Health Care Research, Berlin, Germany; ${ }^{2}$ University Children's Hospital Tuebingen, Center for Pediatric Rheumatology, Autoinflammation Reference Centre Tuebingen (arcT), Tuebingen, Germany; ${ }^{3}$ Charité University Medicine Berlin, Department of Pediatric Pneumology and Immunology, Berlin, Germany; ${ }^{4}$ Clementine Children's Hospital, Rheumatology for Children and Adolescents, Frankfurt/Main, Germany; ${ }^{5}$ Helios Klinik Berlin-Buch, Department of Paediatrics, Berlin, Germany; ${ }^{6}$ Asklepios Clinic, Paediatric Rheumatology Centre, Sankt Augustin, Germany; ${ }^{7}$ German Center for Paediatric and Adolescent Rheumatology, Motion Analysis, GarmischPartenkirchen, Germany; ${ }^{8}$ Vivantes Hospital im Friedrichshain, Children's Hospital, Berlin, Germany; ${ }^{9}$ Charité University Medicine Berlin, Department of Rheumatology and Clinical Immunology, Berlin, Germany

Background: Physical activity (PA), including sport participation is essential for children throughout their growth and maturation. It improves physiological and psychosocial health and limits the risk of developing metabolic disorders. The beneficial effect of PA specifically in patients with JIA has also been linked to its potential regulatory effect on the balance between pro- and anti-inflammatory responses [1].

Objectives: The study aimed i) to quantify the frequency of PA and participation in (organised) sports compared to the general population, ii) to determine self-reported reasons for not practicing sports, and iii) to identify clinical parameters associated with non-participation in sports.

Methods: Data from children and adolescents with JIA recorded in the National Paediatric Rheumatological Database (NPRD) in the year 2019 were considered for the analyses. In accordance with the methodology used in the general population survey (KIGGS) [2], achievement of the WHO recommendations on PA for at least 60 minutes per day as well as sport-related data were determined on the basis of self-reported outcomes in individuals aged 3 to 17 years. In order to compare PA-related data with the general population, a sex- and age-matched sample was drawn. A logistic regression model was used to explore the association between non-participation in sports and patients' clinical outcomes.

Results: Data of 5.333 matched-pairs (mean age $11.0 \pm 4.3$ years, female $67 \%$, patients' disease duration $4.8 \pm 3.8$ years, persistent oligoarthritis $43 \%$ ) were available for evaluation. Almost $38 \%$ of patients aged 3 to 17 years met the recommended PA amount ( $76 \%$ aged 3 to $6 ; 48 \%$ aged 7 to $10 ; 30 \%$ aged 11 to 13 $15 \%$ aged 14 to 17$)$. In matched controls, $21 \%$ fulfilled the WHO recommendations on PA ( $41 \%$ aged 3 to $6 ; 23 \%$ aged 7 to $10 ; 17 \%$ aged 11 to $13 ; 10 \%$ aged 14 to 17). Largest differences across JIA categories were found in persistent oligoarthritis (43\%) and enthesitis-related arthritis (22\%). $64 \%$ of patients and $74 \%$ of controls reported participating in sports, of which $72 \%$ of patients and $58 \%$ of controls stating to participate in a formally organised way. In both groups, boys indicated organised sports participation more often than girls. Among those who declared not participating in sports, "no interest" (patients $27 \%$ vs. controls $29 \%$ ), "no suitable offer nearby" (patients $25 \%$ vs. controls $31 \%$ ), "health restrictions" (patients $22 \%$ vs. controls $4 \%$ ) and "no time" (patients $15 \%$ vs. controls $23 \%$ ) were the most frequently mentioned reasons (multiple responses possible). CJADAS-10 $(\mathrm{OR}=1.02,95 \% \mathrm{Cl}=1.00-1.04), \mathrm{CHAQ}(\mathrm{OR}=1.79,95 \% \mathrm{Cl}=1.50-$ 2.14), DMARD use $(\mathrm{OR}=1.32,95 \% \mathrm{Cl}=1.15-1.53)$ and disease duration (OR $=0.97,95 \% \mathrm{Cl}=0.95-0.99)$ were significantly associated with non-participation in sports.

Conclusion: Based on self-reported data, children and adolescents with JIA meet the WHO recommendation on PA more often than general population controls. Patients are less frequently engaged in sports, but more often involved in formally organised forms. In order to bring joyful, interesting PA opportunities in line with WHO recommendations, further components (e.g. intensity), facilitators and barriers to PA and sports need to be addressed in the future while controlling for JADAS and CHAQ.

\section{REFERENCES:}

[1] Rochette E et al. JIA and physical activity: possible inflammatory and immune modulation and tracks for interventions in young populations. Autoimmun Rev 2015;14:726-734.

[2] Finger JD et al. Körperliche Aktivität von Kindern und Jugendlichen in Deutschland - Querschnittergebnisse aus KiGGS Welle 2 und Trends. Jour nal of Health Monitoring 2018;3:24-31.

Acknowledgements: The National Paediatric Rheumatological Database has been funded by AbbVie, Chugai, Novartis and GSK.

Disclosure of Interests: Florian Milatz: None declared, Martina Niewerth: None declared, Jens Klotsche: None declared, Jana Hörstermann: None declared, Sandra Hansmann: None declared, Tilmann Kallinich: None declared, Christoph Rietschel: None declared, Ralf Trauzeddel: None declared, Joachim Peitz: None declared, Matthias Hartmann: None declared, Hermann Girschick: None declared, Kirsten Minden Speakers bureau: Pfizer, AbbVie, Consultant of: Novartis.

DOI: 10.1136/annrheumdis-2021-eular.2356

\section{POS0078 \\ CROSS-SECTIONAL ANALYSIS OF INTERFERON SIGNATURE IN PEDIATRIC SYSTEMIC LUPUS ERYTHEMATOSUS}

R. Raupov ${ }^{1}$, E. Suspitsin ${ }^{2,3}$, E. Kalashnikova ${ }^{1}$, N. Lybimova ${ }^{4}$, E. Kuchinskaya ${ }^{4}$, R. Mulkidzhan ${ }^{2}$, A. Kosmin ${ }^{2}$, M. Kostik ${ }^{1,4}$. ${ }^{1}$ Saint-Petersburg State Pediatric Medical University, Department of Hospital Pediatrics, Saint-Petersburg, Russian Federation; ${ }^{2}$ N.N.Petrov Institute of Oncology, Molecular diagnostics, Saint-Petersburg, Russian Federation; ${ }^{3}$ Saint-Petersburg State Pediatric Medical University, Department of Medical Genetics, Saint-Petersburg, Russian Federation; ${ }^{4}$ Almazov National Medical Research Centre, Pediatrics, SaintPetersburg, Russian Federation

Background: the role of interferon pathways in the pathogenesis of systemic lupus erythematosus (SLE) has been proven over the past years. Existing data suggest that interferon score (IFN I score) may serve as a useful marker of disease activity and patient clinical characteristics.

Objectives: to compare characteristics of pediatric SLE patients with high and normal IFN I score.

Methods: 40 SLE patients (33 girls, 7 boys) under 18 years old were included in the cross-sectional study. In all cases the diagnosis was made using Systemic Lupus International Collaborating Clinics (SLICC) classification criteria. The data on clinical manifestations, disease activity by SLEDAI and ECLAM, laboratory findings in the onset of the disease and at the moment of interferon signature assessment were evaluated. Interferon signature was assessed by real-time PCR quantitation of 5 IFN I-regulated transcripts; median expression of $\geq 2$ was considered as a threshold. The patients were divided into 2 groups depending on the level of interferon score: high (group1, $n=31$ ) and normal (group2, $n=9$ ).

Results: The mean age of the disease onset was $12(9.5 ; 14.0)$ years. The most common symptoms were skin lesions $(85 \%)$, arthritis $(67.5 \%)$, fever $(55 \%)$ mucosa (45\%), CNS (37.5\%) and kidney (30\%) involvement. Anemia, leukopenia and thrombocytopenia were observed in $62.5 \%, 27.5 \%$ and $50 \%$ of cases 
while $87.5 \%$ and $70 \%$ of patients had ANA positivity and dsDNA antibodies at the onset. The comparison between the groups with increased and normal IFN I-signature is presented in Table 1.

Table 1.

\begin{tabular}{lccc}
\hline Parameters & $\begin{array}{c}\text { Group 1 } \\
\text { (High IFN-s) }\end{array}$ & $\begin{array}{c}\text { Group 2 } \\
\text { (Normal IFN-s) }\end{array}$ & p-value \\
\hline Girls, $\mathrm{n}(\%)$ & $25(80.7)$ & $8(88.9)$ & 0.567 \\
The onset age, years & $12.0(10.0 ; 14.0)$ & $11.0(9.0 ; 13.0)$ & 0.353 \\
Time to IFN-signature study, months from onset & $18.3(7.0 ; 26.5)$ & $0.97(0.87 ; 1.73)$ & 0.987 \\
Skin involvement, $\mathrm{n}(\%)$ & $12(38.7)$ & $4(44.4)$ & 0.837 \\
CNS involvement, n(\%) & $8(25.8)$ & $1(11.1)$ & 0.353 \\
Arthritis, n(\%) & $11(35.5)$ & $2(22.2)$ & 0.455 \\
Anemia, n(\%) & $9(29.0)$ & $2(22.20$ & 0.687 \\
Leucopenia, n(\%) & $9(29.0)$ & $1(11.1)$ & 0.274 \\
ANA-positivity, n (\%) & $27(87.1)$ & $5(55.6)$ & 0.037 \\
anti dsDNA antibodies, n(\%) & $12(38.7)$ & $2(22.2)$ & 0.361 \\
Rheumatoid factor, $\mathrm{n}(\%)$ & $11(35.5)$ & $0(0.0)$ & 0.036 \\
Hypocomplementemia, n (\%) & $18 / 28(64.3)$ & $2 / 6(33.3)$ & 0.162 \\
Ferritin level, mkg/l & $112.0(39.0 ;$ & $21.0(5.3 ; 23.7)$ & 0.0008 \\
& $271.0)$ & & \\
Hematuria, $\mathrm{n}(\%)$ & $10(32.3)$ & $0(0.0)$ & 0.049 \\
Proteinuria, $\mathrm{n}(\%)$ & $11(35.5)$ & $0(0.0)$ & 0.036 \\
SELENA-SLEDAl, points & $9(2 ; 15)$ & $1(0 ; 4)$ & 0.073 \\
ECLAM, points & $3.0(1.0 ; 6.0)$ & $1.0(0.0 ; 1.5)$ & 0.048 \\
Treatment with Rituximab or Cyclophosphamide, & $22(71.0)$ & $3(33.3)$ & 0.040 \\
$\quad \mathrm{n}(\%)$ & & & \\
GCS dose 0,2 mg/kg achievement for 6 months, & $9 / 21(42.9)$ & $5 / 6(83.3)$ & 0.080 \\
$\quad \mathrm{n}(\%)$ & & &
\end{tabular}

Conclusion: high IFN I-signature correlated with kidney involvement, ANA and RF-positivity, ferritinemia, proteinuria and hematuria. Patients with high IFN I-signature received more aggressive treatment and needed longer glucocorticosteroid (GCS) treatment. More meticulous dynamic evaluation of IFN-signature is needed to clarify its role as a predictive and prognostic marker.

Acknowledgements: This work was supported by the RSF grant № 20-45-01005.

Disclosure of Interests: None declared.

DOI: 10.1136/annrheumdis-2021-eular.1956

\section{\begin{tabular}{|l|l}
\hline POS0079 PATIENTS WITH JUVENILE SYSTEMIC SCLEROSIS \\
\hline
\end{tabular} HAVE A DISTINCT PATTERN OF ORGAN INVOLVEMENT.RESULTS FROM THE JUVENILE SYSTEMIC SCLEROSIS INCEPTION COHORT. WWW. JUVENILE-SCLERODERMA.COM}

I. Foeldvari ${ }^{1}$, J. Klotsche ${ }^{2}$, O. Kasapcopur ${ }^{3}$, A. Adrovic ${ }^{3}$, K. Torok ${ }^{3}$, M.

T. Terreri ${ }^{3}$, A. P. Sakamoto ${ }^{3}$, B. Feldman ${ }^{3}$, V. Stanevicha ${ }^{3}$, J. Anton ${ }^{3}$, F

R. Sztajnbok ${ }^{3}$, R. Khubchandani ${ }^{3}$, E. Alexeeva ${ }^{3}$, M. Katsikas ${ }^{3}$, S. Sawhney ${ }^{3}$

V. Smith ${ }^{3}$, S. Appenzeller ${ }^{3}$, T. Avcin ${ }^{3}$, M. Kostik ${ }^{3}$, T. Lehman $^{3}$, E. Marrani ${ }^{3}$,

D. Schonenberg ${ }^{3}$, W. A. Sifuentes-Giraldo ${ }^{3}$, N. Vasquez-Canizares ${ }^{3}$,

M. Janarthanan ${ }^{3}$, M. Moll ${ }^{3}$, D. Nemcova ${ }^{3}$, A. Patwardhan ${ }^{3}$, M. J. Santos ${ }^{3}$,

C. Battagliotti ${ }^{3}$, L. Berntson ${ }^{3}$, B. Bica ${ }^{3}$, J. Brunner ${ }^{3}$, R. Cimaz ${ }^{3}$, P. Costa Reis ${ }^{3}$

D. Eleftheriou ${ }^{3}$, L. Harel ${ }^{3}$, G. Horneff ${ }^{3}$, S. Johnson ${ }^{3}$, D. Kaiser ${ }^{3}$, T. Kallinich ${ }^{3}$,

D. Lazarevic ${ }^{3}$, K. Minden ${ }^{2}$, S. Nielsen ${ }^{3}$, F. Nuruzzaman ${ }^{3}$, S. Opsahl Hetlevik ${ }^{3}$,

Y. Uziel ${ }^{3}$, N. Helmus ${ }^{1} .{ }^{1}$ Hamburg Centre for Pediatric and Adolescent Rheumatology, Schön Klinik Hamburg Eilbek, Hamburg, Germany; ${ }^{2}$ German Rheumatism Research Center, German Rheumatism Research Center, Berlin, Germany; ${ }^{3}$ jSSc Collaborative Group, Hamburg Centre for Pediatric and Adolescent Rheumatology, Hamburg, Germany

Background: Juvenile systemic sclerosis (jSSc) is a rare disease with a prevalence of around 3 in 1,000,000 children. To better capture the clinical manifestations of jSSc the juvenile systemic sclerosis inception cohort (jSScC) has been prospectively enrolling patients with predetermined clinical variables over the past 12 years. One of the goals is to study the demographic, clinical features, and physician and patient reported outcome differences between those with juvenile limited cutaneous (Ic) compared to diffuse cutaneous (dc) disease subtypes, to determine if characteristics are similar or different between dc and lc jSSc.

Objectives: Evaluation of the baseline clinical characteristics of jSSc patients in the jSScC. Compare clinical phenotype between diffuse (dcjSSc) and limited cutaneous (IcjSSc) subtypes

Methods: Demographic, physical examination, organ system evaluation, autoantibody profile, treatment, and patient and physician reported outcome variables were evaluated from the jSSc Inception cohort and summary statistics applied using chi-square test and Mann Whitney U-test comparing IcjSSc and dcjSSc subtypes.

Results: At the time of data extraction, 175 jSSc patients were enrolled in the cohort, $81 \%$ were Caucasian and $81 \%$ female. Diffuse cutaneous jSSc subtype predominated $(73 \%)$. Mean disease duration was 3.1 year $( \pm 2.7)$. Mean age at
Raynaud's was 10 years (+3.8) and mean age of first non-Raynaud's was 10.2 years $( \pm 3.8)$. Significant differences were found between dcjSSc versus IcjSSc, regarding several clinical characteristics. Patients with diffuse cutaneous subtype had significantly higher modified Rodnan skin score $(p=0.001)$, presence of sclerodactyly ( $p=0.02)$, presence of Gottron's papules $(p=0.003)$, presence of telangiectasia $(p=0.001)$, history of digital tip ulceration $(p=0.01)$, and frequency of elevated CK value $(p=0.04)$. Cardiac involvement was significantly higher in limited cutaneous jSSc subtype $(p=0.02)$. Diffuse cutaneous jSSc patients had significantly worse scores for Physician Global Assessment of disease activity ( 38 vs $25 ; p=0.002$ ) and disease damage (34 vs $19 ; p=0.008$ ).

Table 1. Comparison of demographic data and significant differences between dcjSSc and IcjSSc at time of inclusion

\begin{tabular}{|c|c|c|c|c|}
\hline & $\begin{array}{l}\text { Whole Cohort } \\
\qquad \mathrm{N}=175\end{array}$ & $\begin{array}{c}\text { Diffuse } \\
\text { Subtype } \\
N=128\end{array}$ & $\begin{array}{c}\text { Limited } \\
\text { Subtype } \\
\mathrm{N}=47\end{array}$ & $\begin{array}{c}P \\
\text { value }\end{array}$ \\
\hline $\begin{array}{l}\text { Female to Male Ratio } \\
\text { Cutaneous subtype }\end{array}$ & 4.3:1 (142/33) & $4.1: 1(103 / 25)$ & $4.8: 1(39 / 8)$ & 0.829 \\
\hline Diffuse subtype & $73 \%(128)$ & 128 & 0 & \\
\hline Limited subtype & $27 \%(47)$ & 0 & 47 & \\
\hline $\begin{array}{l}\text { Mean Disease duration } \\
\text { (years) }\end{array}$ & $3.1( \pm 2.7)$ & $3.3( \pm 2.9)$ & $2.6( \pm 2.2)$ & 0.135 \\
\hline $\begin{array}{l}\text { Mean age of onset of } \\
\text { Raynaud's (years) }\end{array}$ & $\begin{array}{c}10.0( \pm 3.8) \\
17 \text { non-Raynaud }\end{array}$ & $\begin{array}{c}9.8( \pm 3.6) \\
10 \text { non-Raynaud }\end{array}$ & $\begin{array}{c}10.6( \pm 4.3) \\
7 \text { non-Raynaud }\end{array}$ & 0.219 \\
\hline $\begin{array}{l}\text { Mean age of onset of } \\
\text { non-Raynaud's (years) }\end{array}$ & $10.2( \pm 3.9)$ & $10.0( \pm 3.7)$ & $10.9( \pm 4.3)$ & 0.173 \\
\hline $\begin{array}{l}\text { Disease modifying drugs } \\
\text { Cutaneous }\end{array}$ & $88 \%(154)$ & $89 \%(114)$ & $85 \%(40)$ & 0.446 \\
\hline $\begin{array}{l}\text { Mean modified Rodnan skin } \\
\text { score }\end{array}$ & $14.3(0-51)$ & $17.4(0-51)$ & $6.1(0-24)$ & 0.001 \\
\hline Gottron Papules & $27 \%(46 / 171)$ & $33 \%(41 / 124)$ & $11 \%(5)$ & 0.003 \\
\hline Sclerodactyly & $78 \%(126 / 162)$ & $82 \%(98 / 119)$ & $65 \%(28 / 43)$ & 0.020 \\
\hline Laboratory values & $25 \%(30 / 122)$ & $30 \%(26 / 88)$ & $12 \%(4 / 34)$ & 0.041 \\
\hline \multicolumn{5}{|l|}{ Elevated CK } \\
\hline Telangiectasia & $36 \%(56 / 154)$ & $44 \%(49 / 111)$ & $16 \%(7 / 43)$ & 0.001 \\
\hline History of ulceration & $53 \%(91 / 173)$ & $61 \%(77 / 127)$ & $30 \%(14 / 46)$ & 0.001 \\
\hline $\begin{array}{l}\text { Cardiac } \\
\text { Cardiac Involvement }\end{array}$ & $6 \%(10)$ & $2 \%(3)$ & $15 \%(7)$ & 0.002 \\
\hline Patient Related Outcomes & & & & \\
\hline $\begin{array}{l}\text { Physician global disease } \\
\text { activity } \\
(0-100) \text { min - max }\end{array}$ & $\begin{array}{c}35 \\
(0-90) n=141\end{array}$ & $\begin{array}{c}38 \\
(0-90) n=108\end{array}$ & $\begin{array}{c}25 \\
(0-80) n=33\end{array}$ & 0.002 \\
\hline $\begin{array}{l}\text { Physician global disease } \\
\text { damage } \\
(0-100) \text { min - } \max \end{array}$ & $\begin{array}{c}31 \\
(0-85) n=140\end{array}$ & $\begin{array}{c}34 \\
(0-85) n=108\end{array}$ & $\begin{array}{c}19 \\
(0-60) n=32\end{array}$ & 0.008 \\
\hline
\end{tabular}

Conclusion: Results from this large international cohort of jSSc patients demon strate significant differences between dcjSSc and IcjSSc patients. According to the general organ involvement and physician global scores, the dcjSSc patients had significantly more severe disease. These observations strengthen our previous findings of the unique organ pattern of pediatric patients.

Supported by the "Joachim Herz Stiftung"

Disclosure of Interests: None declared.

DOI: 10.1136/annrheumdis-2021-eular.799

\section{\begin{tabular}{|l|l}
\hline POS0080 TOFACITINIB TREATMENT IN CHILDREN WITH \\
\hline
\end{tabular} RHEUMATIC DISEASES: SINGLE-CENTER EXPERIENCE}

M. Kostik ${ }^{1}$, R. Raupov ${ }^{1}$, E. Suspitsin ${ }^{2}$, E. Isupova ${ }^{1}$, T. Gabrusskaya ${ }^{3}$, M. Dubko ${ }^{1}$ L. Snegireva ${ }^{1}$, V. Masalova ${ }^{1}$, T. Ermachenkova ${ }^{2}$, L. Sorokina ${ }^{1}$, T. Likhacheva ${ }^{1}$, M. Kaneva ${ }^{1}$, E. Gaidar ${ }^{1}$, O. Kalashnikova', V. Chasnyk' ${ }^{1}{ }^{1}$ Saint-Petersburg State Pediatric Medical University, Hospital Pediatrics, Saint-Petersburg, Russian Federation; ${ }^{2}$ N.N.Petrov Institute of Oncology, Molecular diagnostics, SaintPetersburg, Russian Federation; ${ }^{3}$ Saint-Petersburg State Pediatric Medical University, Gastoenterology, Saint-Petersburg, Russian Federation

Background: While efficacy of tofacitinib (TOF) has been proven in many adult immune-mediated conditions, the information on its' safety and efficacy in the pediatric population is limited.

Objectives: to evaluate the safety and efficacy of TOF in children with immune-mediated diseases.

Methods: from 23 children whom TOF has been initiated, 17 children with treatment duration of $>6$ months were extracted including 16 girls and 1 boy with the following diagnosis: JIA $(n=10)$, autoinflammatory diseases (AID) $(n=5)$ and juvenile dermatomyositis (JDM) $(n=2)$ due to impossibility to taper corticosteroids (CS) or previous biologic treatment failed. The treatment outcome was classified according to the opinion of the attending physicians as complete response (CR) i.e., the absence of disease activity, partial response (PR) - a significant 